\title{
EMBATES DEL HUMOR EN GREY DE ALBERTO CHIMAL
}

\author{
Elsa López Arriaga \\ Universidad Veracruzana \\ elsalopar@gmail.com
}

RESUMEN: Este trabajo presenta un estudio de la ironía como elemento articulador del discurso narrativo en Grey (2006) de Alberto Chimal, a través del acercamiento a distintos mecanismos operantes como la burla, el contraste, la ambivalencia y la antífrasis para mostrar críticamente las debilidades, contradicciones o inconsistencias de las diversas estructuras religiosas, y para orientar la reflexión hacia las múltiples manifestaciones de la fe, a veces contrapunteadas con la naturaleza humana.

PALABRAS CLAVE: ironía, humor, Grey, Alberto Chimal

\begin{abstract}
This paper presents a study of the irony as a substantial construction of the narrative discourse in Alberto Chimal's Grey (2006), from the approaches of different operative mechanisms such as teasing, contrast, ambivalence, and antiphrasis to critically show weaknesses, contradictions or inconsistencies of various religious structures, and to guide reflection towards the multiple manifestations of faith, sometimes counterpointed with human nature.
\end{abstract}

KEYWORDS: irony, humor, Grey, Alberto Chimal

Si Dios creó a la humanidad, entonces Él es el primer doctor Frankenstein de la Historia.

RENÉ AVILÉS FABILA

Según afirma Ángel Rama en su ensayo "El boom en perspectiva", la publicación de la novela Cien años de soledad (1967) de Gabriel García Márquez "dio contextura al aún fluyente e indeciso boom, le otorgó forma y en cierto modo lo congeló como para que pudiera comenzar a extinguirse" (2005: 188). Cien años, una novela sin parangón, determinó el momento álgido y el fin de un fenómeno literario, con esto, dio inicio también a una nueva etapa poética en Latinoamérica. La literatura latinoamericana, tras haber sufrido los embates de radicales innovaciones durante las décadas de los cincuenta y sesenta, empieza a resguardarse en formas más tradicionales. Aunque median treinta años, este momento transicional sigue considerándose determinante para la producción narrativa de la última década. 
En el caso de la narrativa mexicana, el final del "boom" coincide con una de las circunstancias más importantes que cambiaría el rumbo de la cultura en México: la matanza de estudiantes en 1968, cuando se señaló abiertamente a los intelectuales mexicanos como los principales actores del evento. Es entonces cuando empieza el periodo de "la crisis" mexicana, agudizado cada vez más no solo por tres crisis económicas (1976, 1980 y 1994), sino por la desesperanza afincada en la mentira política acompañada de la oscuridad del futuro de los jóvenes mexicanos. Además, los años finiseculares abrieron una herida en las letras mexicanas con la muerte de Rulfo en 1986, Octavio Paz y Elena Garro en 1998 y Juan José Arreola en 2001. La primera década del nuevo siglo trajo consigo también la pérdida de Carlos Fuentes, Salvador Elizondo, Juan García Ponce, Fernando Benítez, Carlos Monsiváis, Vicente Leñero, entre tantos otros, voces que abrigaron la literatura mexicana del siglo XX, y cuya sombra se levanta siempre tras los hombros de los nuevos escritores, para quienes la gloria estará delineada por los titanes del "boom" y de la Generación del Medio Siglo como predecesores.

En este panorama del cambio de siglo tienen su auge los narradores mexicanos nacidos en la década de los setenta, se trata de "una generación huérfana y dispersa [...] se puede hablar de que ésta es la primera generación que comenzó a escribir y publicar sin la sombra de una figura patriarcal y hegemónica" (Maldonado, 2008:11). Julián Herbert, Antonio Ortuño, Gabriela Valenzuela, Heriberto Yépez, Guadalupe Nettel, Luigi Amara, Yuri Herrera, David Miklos y Alberto Chimal ${ }^{1}$ son los escritores de la generación de los setenta más prolíficos y más reconocidos, nombres comunes en suplementos culturales, periódicos o blogs, y en encuentros, conferencias o congresos académicos.

Los escritores mexicanos nacidos en los setenta forman parte de una generación que hasta ahora ha recibido múltiples motes: Generación inexistente, Generación sin generación, Generación del caos, Generación de la Crisis, Generación Y o, como les denomina Alberto Chimal (2011), Generación Z. Para este autor, forman la generación zombie quienes, después de los noventa han

tenido que recurrir a una de dos estrategias: no morirnos, resistir, o bien sí morirnos: dejar de existir como los escritores que éramos y volver como otros después de un periodo de silencio. El descalabro del fin de siglo afectó a todos, pero no destruyó a quienes tuvieron la terquedad suficiente para continuar a pesar del quiebre de sus intereses y de su ambiente, sin otra protección que su trabajo, o bien fueron capaces de encontrar otro sitio desde el que escribir: otros temas, otros enfoques, otra relación con su propia voz y con el mundo.

Más allá de nombre utilizado para reconocer a este grupo de narradores mexicanos y pese a los intentos de clasificarlos desde la aparente dispersión en su literatura, no pueden negarse las afinidades en la obra de estos autores:

Narradores pasivos y contemplativos, tramas casi desprovistas de acontecimientos —aunque algunas de sus premisas iniciales fueran estrambóticas o escandalosas-, un ambiente urbano y

\footnotetext{
${ }^{1}$ De acuerdo con Tryno Maldonado, de este grupo de autores, Alberto Chimal fue el primero al que se le dedicó un volumen de estudios críticos: Mito, fantasía y recepción en la obra de Alberto Chimal (Samuel Gordon [comp.], México, Eón, 2006). Véase "Intro", en Tryno Maldonado (ed.), Grandes hits. Nueva generación de narradores mexicanos, vol. I, México, Almadía, 2008, 21.
} 
contemporáneo visto de manera no desapasionada pero sí distante y, sobre todo, una sensación de desencanto: profunda melancolía que desembocaba en amargura, en efusiones sentimentales o en observaciones cínicas sobre una realidad hostil. (Chimal, 2011)

A cambio de rasgos como complejidad estructural, transgresión del espacio y el tiempo o tramas laberínticas, los narradores nacidos en los setenta regresan a las estructuras sencillas y apuestan por una literatura accesible para el lector. Con todo, crean desde la hibridez genérica y transgreden los cánones empleando diversas formas del humor - como parodia, ironía, sátira, carnavalización o deformación grotesca-, explorando así las posibilidades de configuración de universos alternos regidos por la búsqueda de sentido, de este modo se ponen a prueba los lindes aparentemente inamovibles de la realidad. Los escritores zombis, dice Chimal, modifican el lenguaje, trastocan los géneros, sus textos no atienden a la prosodia ni a la fórmula, "su fuerza es diferente: terca, díscola, y sus palabras son más enérgicas que las de un primerizo, y más desesperadas. En esto también se parecen a los zombis: ya no los pueden matar porque ya han muerto. Resisten y continúan" (2011).

Testigos de los alcances y posibilidades que trajo consigo el crecimiento exponencial del ciberespacio, tienen como principal recurso de trabajo la computadora y como medios de difusión de su literatura las redes sociales y los blogs. La publicación automática facilitada por Internet es una tentación a la que pocos han logrado resistirse, con esto, han abierto nuevas vetas para la creación literaria en cuanto a su extensión y forma - no es gratuito, por ejemplo, su impacto en la minificción de los siglos XX y XXI-, pero también respecto a su difusión. Como afirma Maldonado, "Internet ha ayudado a abrir canales de información más dinámicos y a crear la sensación de una dispersión de poder del centro" (2008: 11). En efecto, la descentralización de la literatura mexicana, según considera Ortuño, representa "la ruptura de un paradigma que durante mucho tiempo fue inamovible: nacieran donde nacieran los autores, la literatura visible se difundía desde la capital, se narraba desde la capital y desde la lógica de las hegemonías que la capital trae consigo: poder político, económico y cultural" (Herbert/Ortuño, 2014: 41); y las nuevas miras del mercado editorial dan cuenta, dice Julián Herbert, de un "interés generacional en Latinoamérica, potenciado por el uso de las redes sociales" (Herbert/ Ortuño, 2014: 40). La obra cuentística de los narradores nacidos en los setenta es prueba innegable del cambio de modelos y del uso de nuevos recursos de construcción y difusión de la obra literaria, todo ello permite dilucidar sus particularidades históricas y culturales.

La obra cuentística de Alberto Chimal (Toluca, Estado de México, 1970) es reconocida desde temprano por la construcción de mundos distintos a la realidad evidente, sobre todo en libros como La luna y los 37,000,000 de libras (1990), Tradiciones y leyendas (1996), Vecinos de la Tierra (1996) y El ejército de la Luna (1998). Su trayectoria creativa, conformada por más de treinta publicaciones, es vasta y heterogénea, va desde el relato breve, el cuento, el ensayo y la novela, y se extiende hasta la traducción y la novela gráfica.

En 2006, año en que ve la luz su volumen de cuentos Grey, Chimal contaba con muchas publicaciones notables. Además de las ya mencionadas, gozaban ya de reconocimiento sus libros de cuentos Gente del mundo (1998), El país de los hablistas (2001) y Estos son los días (2004); 
así como su libro de ensayos La cámara de maravillas (2003); dos obras de teatro: El secreto del Gorco (1997) y Canovacci (1998); y la novela gráfica titulada Horacio en las ciudades (2004). De los escritores de su generación, podría mencionarse a Chimal como quien ha conseguido consolidar su carrera de manera más contundente.

La aparición de Grey significó para Alberto Chimal la oportunidad de expandir los horizontes de sus intereses temáticos y voltear la mirada a la reflexión de la naturaleza religiosa. En este texto, destaca como rasgo medular la mordacidad oscilante entre la burla y la ironía procurando no solo el valor estético de la obra sino su conformación crítica. Chimal muestra un mundo agnóstico y fragmentario, donde los recursos humorísticos se revelan en las contradicciones, incongruencias y dificultades características del ser humano cuando intenta comprender lo divino y llevar a la práctica cotidiana lo inefable.

Los estudios críticos sobre la obra de este autor destacan la creación de universos alternos capaces de poner en tela de juicio los alcances y límites de la realidad, en este sentido, "los fenómenos religiosos (estigmas, resurrecciones) son un caso especial: se mueven en las fronteras de lo fantástico, lo maravilloso o de lo realista, dependiendo de la laicidad del escritor y de los lectores" (Avilés, 2013:18). Más allá de los elementos fantásticos o maravillosos, Chimal llega a tensar, en Grey, los límites de la cotidianidad, donde emergen nuevas posibilidades de la experiencia humana y se desvela la irreverencia. Este volumen de cuentos lleva al extremo la forma de pensar lo divino: desde el desenfado, rozando por momentos lo siniestro. De los hechos extraordinarios, las representaciones de figuras míticas y lo ominoso, la narrativa de Chimal deviene, en Grey, humorística y crítica.

En la introducción a una breve entrevista publicada en 2009, Jorge Luis Herrera asegura: "su literatura describe mundos ficticios que no se comprenden con las «reglas» de la lógica dominante en el «mundo real» y, por lo general, no sujetos a las leyes físicas del espacio y el tiempo. Con frecuencia plantea problemáticas de la condición humana a través de la fantasía y la imaginación" (Herrera, 2009: 181). Si se piensa este volumen de cuentos en tanto representación de la realidad de valores imaginarios desplegados en la construcción textual, sus significaciones se potencian cuando aumentan los mecanismos de fabulación. Al respecto, Chimal acepta este recurso como punto articulador de su narrativa: "descubrí que la posibilidad de imaginar, de concebir ideas, historias, fragmentos de vida que no son los del mundo «real», era reconfortante, no sólo para escapar, sino también para imaginar alternativas: para convencerme de que aquellos hechos y circunstancias que parecen inevitables en el mundo, desde los muy personales hasta los más generales, no lo son" (Herrera, 2009: 183). Revelar sutilmente "las alternativas" subyacentes a los hechos cotidianos del mundo parece ser la tarea impuesta por el autor en Grey, quien, dice Elsa Treviño, "cuestiona la función mimética de la literatura al crear mundos ficcionales que, en lugar de ser imitaciones o reproducciones del mundo real, tienen una lógica propia incongruente con la lógica propia fuera del mundo del texto" (2013: 82).

El efecto de la imaginación volcada en escritura pone de manifiesto el estilo narrativo, consolidado por el humor, característico de Grey: la ruptura del mundo rígido y ortodoxo de la estructura religiosa ante las alternativas de significación gestadas en la ambivalencia de ese 
mismo discurso. La problemática de la creencia y de la institución religiosa es puesta en vilo desde la crítica emanada de la figuración irónica.

Creador de textos breves, a veces brevísimos como es el caso de su libro 83 novelas ejemplo fundamental de la trasmutación de la literatura en la era digital, pues cada breve "novela" tuvo su origen en los caracteres permitidos de una cuenta de Twitter-, Chimal lleva al extremo la expresión mínima del cuento. Con esto, bajo la premisa de "menos es más", se magnifican los horizontes significativos de cada texto, tal como el autor explica al principio de 83 novelas: "los mundos narrados son pequeñísimos en la página pero se amplifican en la imaginación" (Chimal, 2010: 5). Aunque la extensión de la minificción se considera entre una línea y una página, debe reconocerse la flexibilidad de estos márgenes. En Grey se encuentran algunos cuentos de más de cinco páginas, pero no dejan de ser fugaces, depositando en los espacios vacíos la mayor carga significativa. La naturaleza del relato breve induce la incertidumbre del lector a partir de ciertos elementos narrativos: "disminuyen casi toda descripción hasta convertirla en insinuación; eliminan las digresiones, evitando cualquier tramo - cualquier desvío - que no implique un avance o progreso en la acción" (Lagmanovich, 2009: 89). Los juegos de la imaginación realizados por Chimal depositan su sentido en la actividad lectora, en la exigencia de la competencia narrativa para dar sentido a la parte invisible de lo escrito.

Como el nombre del libro anuncia, las anécdotas contadas forman un tejido en función del discurso religioso. La grey es congregada en la brevedad y representada en sus múltiples facetas, todas ellas cuestionadas desde su manifestación en la cotidianidad. Los cuarenta y un cuentos agrupados en cuatro secciones ("Tanto gusto", "Manda fuego", "La pasión según la sombra" y "Cuenta", estos títulos, además de dar nombre a los cuentos más extensos del volumen, guían la temática de las ficciones consecuentes) nutren la multiplicidad de enfoques: relatan la práctica religiosa, la base dogmática de la fe, la búsqueda de la salvación, el quebrantamiento del discurso bíblico y las manifestaciones públicas de los creyentes.

\section{Dissimulatio: la ironía como juego de apariencias}

La figuración irónica pone en juego diversos recursos del lenguaje y de la ficción, tales como la ambivalencia, la contradicción y la transgresión. Estos aspectos comportan una visión de mundo enunciada por el narrador, quien pretende relativizar los "absolutos" de la estructura religiosa tomando como punto de partida la distorsión de lo divino en el entendimiento del ser humano.

La narración dota a la ironía de un factor determinante, pues, a diferencia de otros modos discursivos, ofrece "la posibilidad de gobernar todos sus niveles de significación, extremando los contrastes entre la visión de los personajes, la de los lectores y la del narrador" (Ballart, 1994: 375). En Grey, la doble visión propia de la ironía anida en el equilibrio entre realidad y ficción, verdad y mentira, broma y seriedad. Ante la ausencia de enunciación explícita de este doble juego de sentidos, el narrador, como dissimulatio, expone las cosas como son - "se simula lo que no es, se disimula lo que es", dice Accieto en su Tratado sobre la disimulación honesta (citado por Eremiev, 2009: 170)—, pero mantiene una apariencia prudente, un encubrimiento, que lo ubica al 
margen de la crítica y los juicios de valor solo sugeridos, permitiéndole mantener la distancia con el hecho ironizado.

El narrador irónico, desde un juego de apariencias, expone el bien y el mal como partes de una paradoja inexistente, es decir, la contraposición de ambos términos se anula debido a su similitud lógica que funciona a partir de la culpa. En el relato "Previsión", se expone al hombre ante la contradicción de la práctica dogmática, donde se privilegia el juicio moral y cuyo único resultado posible es la represión. El relato describe una casa de citas visitada por los "hombres de bien", con la intención de sosegar su deseo sexual, para conseguirlo sin quebrantar las normas impuestas por el dogma religioso, la liberación buscada se consuma a través de la represión:

Nuestra casa tenía, para esos clientes, cuartos con muchachas totalmente vestidas, que se dedicaban a regañarlos, a llamarlos "pecadores", a invocar las leyes divinas y los horrores del infierno, a contraponer éstos a las bellezas de la familia tradicional y casta y luego volver a las descripciones infernales, que siempre son más persuasivas. Si algo, optaban a veces por acusaciones como: — ¿Ya te viste al anillo, animal? ¿Ya viste que traes un anillo? (2006: 25) ${ }^{2}$

La imposición de la culpa en aras de una especie de arrepentimiento anticipado se advierte desde el título del relato, así se reconoce también el sentido del texto: prevenir el pecado. Un espacio completamente inverso a un prostíbulo, donde el cumplimiento del deseo se convierte en represión, marca la lucha irreconciliable entre el deber y el ser del hombre, donde, inevitablemente, el deber siempre resulta triunfante. Bajo el principio canónico de contención del impulso deseante, los clientes, dice el narrador, "que de por sí llegaban acobardados y lelos y nulos por la culpa, podían volver a ponerse la ropa con la conciencia de que no habían llegado a nada" (25). La negación, casi inexistencia de aquel deseo, se convierte en el guiño irónico del narrador cuando concluye el relato con la aclaración entre paréntesis: “(porque allí sólo atendíamos a gente decente)" (25).

La ironía en tanto contradicción situacional emerge, en los cuentos de Grey, en coincidencia con los finales, casi nunca sorpresivos sino ambivalentes que sugieren otra realidad. El final de estos relatos, "aunque no exige en forma absoluta la atónita sorpresa del lector, por lo menos le proporciona cierto conocimiento de carácter conclusivo, sin perderse en vagarosidades ni en una especie de niebla (y mucho menos tiniebla) del significado" (Lagmanovich, 2009: 91). Por esto, las aclaraciones finales entre paréntesis contienen una fuerte carga significativa. En contadas palabras, el narrador sitúa dos posibilidades del discurso irónico: pretende no decir una cosa aunque sí la dice o parece pasar por alto algo pero no lo hace.

La misma voz irónica modifica la expresión del pensamiento a partir del engaño de la apariencia. Así, en "Plenas", el disimulo se asienta en una especie de sarcasmo cuyo sentido se confirma en la irrealidad que se lee en correspondencia con lo narrado. El narrador utiliza una visión distorsionada como vehículo para mostrar la problemática discordante de la verticalidad moral: “«La mujer no está completa si no es madre». «La mujer no está completa si no es madre». Tanto lo oyó Irina, de modo tan ferviente lo creyó, que su hija (Irinita, le decían) lo supo ya antes de nacer y el día del parto (¡maravilla del cielo!) ya traía adentro a Irinitita, quien a su

\footnotetext{
${ }^{2}$ Todas las citas del volumen corresponden a esta edición. En adelante solo asentaré el número de la página.
} 
vez..." (68). La aclaración, nuevamente entre paréntesis, velada por un tono de acontecer milagroso denota la ambivalencia sarcástica del discurso.

La visión irónica surgida en la ambigüedad de lo sarcástico cuestiona las formas en las que el hombre pretende acercarse a la divinidad y explicar lo ininteligible. La ambigüedad del disimulo abre un espacio entre la voz irónica y el lector, donde puede diferirse de la verdad enunciada. En los tres cuentos llamados "Catálogo de Sectas", los sarcasmos abundan, pues se convierten en la manera eficaz de quebrantar los "absolutos" religiosos, de relativizarlos a un grado tal que de máximas universales resulten transposiciones cotidianas de cualquier sistema de valores religiosos: "los ofiditas sostienen que la Serpiente era, en verdad, una predicadora de la fe verdadera (!), que habría intentado convertir a Adán y Eva antes de que el hapaxlegómeno (?) naciese destorcido" (11), "[los dulzones] se bautizan por inmersión en miel y las vacaciones de sus recién matrimoniados tienen un nombre más extenso y empalagoso que la presente nota" (11), "la divisa de los mediocritas: —Así soy y qué - se podría juzgar literariamente pobre; pero la tienen a sabiendas. Parten de la idea de que todo está «del carajo», luego, «qué caso tiene»" (39); "andado el tiempo, el cuerpo del santo murió y se disolvió en el sitio de su entierro, con lo que la materia crística pudo abandonar esos restos y viajar al garete por todo el mundo y en infinidad de formas; felizmente, la última fue la brizna de pasto que comió la oveja a la que creció la lana que rasuró el pastor que la vendió a la fábrica que hizo el fieltro que compró el taller que hizo el sombrero negro finísimo qué bonito sombrerito y no se lo quita nunca de Nino Martín Escapulárez" (40); "prosiguen con fervor los desconfiados: — si no se les tortura o (al menos) disciplina adecuada y firmemente para ponerlos en buen sendero, dichos niños (todos) crecen para convertirse en ese horror: el adulto corriente_-" (87) o "los amantes de los gatos los consideran proporciones de la Mente Universal: variable, despreocupada, exigente y cariñosa en ritmos que no puede abarcar nuestra propia conciencia sublunar" (87).

\section{La ironía a medio camino entre dos valores}

Hay en Grey otro tipo de cuestionamiento expuesto por la voz narrativa: la contradicción inherente al hecho de la fe, condenada siempre a la imposibilidad y la pretensión, eficaz únicamente a los ojos del autoengaño del creyente: "el disimulo ante sí mismo se convierte en un medio de alcanzar una forma efímera de felicidad, la cual - a veces - es la única que se puede alcanzar" (Eremiev, 2009: 173). Destaco como ejemplo principal el relato "El que tenga oídos...", transcrito a continuación:

Yo era pobre, vivía mortificado, todos me humillaban. Luego caí enfermo gravemente y aun quienes me odiaban me dieron la espalda. Me encomendé a la gracia de Dios con tal fervor que el Señor se apiadó de mí, y no sólo me alivió sino que me convirtió en un hombre nuevo, totalmente distinto, hasta el punto de que tengo otro nombre y otra fecha de nacimiento, soy de otro país, hablo otra lengua, mi cabello tiene otro color y un remolinito y además no conservo ni un solo recuerdo de mi vida anterior.

(Qué asco de mentiroso que soy, ¿verdad?) (29) 
La ironía se convierte en el engranaje de la materia narrativa. La frase "aun quienes me odiaban me dieron la espalda" denuncia en tono humorístico la hipocresía del creyente en momentos de crisis, la presencia falsa para cumplir con el compromiso espiritual y calmar el ansia de salvación. La eficacia del fervor religioso es solo posible, parece decir el narrador, convirtiéndose en otra persona, pues la existencia atormentada no acepta salvación alguna sino cambiando, literalmente, de vida, para quien presume lograrlo está también la burla final del narrador. En este caso, la enunciación en primera persona consolida el discurso irónico al mimetizar la voz del narrador y la del personaje. La violación del código, religioso en este caso, para transformarlo en materia del lenguaje sirve, dice Ballart, a los fines del ironista, que pretende "parodiar una determinada dicción, un estilo, una manera de razonar" (1994: 368).

Como voz irónica, el narrador logra la significación final del texto utilizando el recurso de la antífrasis —el nivel más evidente de la ironía—, es decir, el camino medio entre dos valores en conflicto. El fenómeno antifrásico surge cuando "conservando una cierta apariencia de verosimilitud en sus enunciados literales, consigue canalizar de una sola vez dos valores argumentativos en conflicto, con lo que el lector que sabe percibirla puede apreciar la distancia que media entre ambos, o, en otras palabras, el desvío de la norma" (Ballart, 1994: 336). De este modo, la ironía permite la edificación del sentido en la posibilidad abierta por la oposición, en el ejemplo mencionado el cambio radical de vida mediante la encomienda a Dios se contrapone con el autoengaño aceptado.

Un caso parecido se da en el relato "El secreto", donde el hombre acude a la comunión asumiendo sus faltas, pero seguro de la superioridad conferida al ser creyente de los milagros. La contradicción irónica yace en el tejido narrativo. Aquí el relato: "La hostia le quema la lengua: cada vez el mismo dolor espantoso, casi imposible de ocultar, pero él lo esconde, se cura con presteza la boca y persiste en sus crímenes, sus burlas de la inocencia, su apoyo del sufrimiento y de la angustia. Es superior a los otros hombres: sabe que existen los milagros" (43). La evocación del falso arrepentimiento y el rito de comunión como un acto de fingida espiritualidad refuerzan el conflicto de ideas detonante de la ironía.

El ethos irónico — que Linda Hutcheon entiende como "una reacción buscada, una impresión subjetiva que es motivada, a pesar de todo, por un dato objetivo: el texto" (1992: 180) — de estos relatos recae en la inaccesibilidad de Dios para el ser humano, sin necesidad de aceptarlo o negarlo. La exploración humana de lo divino aparece como una "suerte de fe en la fantasía de la realidad" (Avilés, 2013: 18). La voz irónica pondera el carácter de "fantasía" detrás de la creencia absoluta en el poder de la fe. La tensión presente en los cuentos ya mencionados se puede apreciar también en el relato "Justo al contrario...":

... que en Sodoma y Gomorra, lo nuevo entre la gente virtuosa es lo que más de un cientificista ha llamado el accidente selectivo. Si su vecino se refocila en cualquiera de las formas de la impiedad, usted reza y reza y reza y pronuncia claramente el nombre del culpable. A la mañana siguiente, éste amanecerá muerto de combustión espontánea, es más, hecho un trozo de carbón, y para más milagro estará sentadito en el lugar que se le había asignado la noche anterior por su vuelo trascontinental, sin que ninguno de los pasajeros a su alrededor haya notado nada. (26) 


\section{El carácter ambivalente en la ironía}

En estrecho vínculo con estas manifestaciones de la figuración irónica, se ubican los textos caracterizados por la oposición presentada más bien como una dualidad. En "La catarata", el sacramento del bautismo confiere al bautizado la luz y oscuridad a través de los nombres: "Mauricio es «oscuro» y Alberto es «brillante»" (21). Las posibles formas de nombrar al infante se presentan como entes del inframundo que objetivan la ambivalencia propia de la naturaleza humana: "Nuestras voces son el rumor del agua que se agita. Abajo, más en lo oscuro, laten los sueños y los monstruos" (21).

Si la ironía es "entendida como uso singular del lenguaje, la literatura favorece que en ese espacio retórico se den desplazamientos, subversiones, desvíos de la norma” (Ballart, 1994: 365), es posible pensar la ambivalencia como medio característico de la ironía para quebrantar el canon religioso. En este sentido, la multifacética moral del ser humano fragmenta los juicios de valor dominantes en el dogma, convirtiéndolos, incluso, en sus contrarios. El cuento "Un amor" pone en conflicto a una pareja de personajes: él era dos hombres: uno "sentía el calor entre las piernas" (27) y el otro rezaba por su alma; ella, igualmente era dos: la virgen y la puta, "Pero una noche en el instante en que se abría la puerta de la habitación, el casto que salía volteó. Miró a la virgen, y se hablaron, y puestos de acuerdo huyeron juntos. Él se convirtió en numerario y ella se hizo monja. Y así los otros dos, abandonados, quedaron dueños de la casa, y nadie más habló de ellos, y fueron felices" (27).

El discurso religioso visto él mismo en su carácter ambivalente conforma un juego de causa-efecto que germina y converge en el mismo punto, como un movimiento circular, por ejemplo, el pecado, creado por la institución religiosa (cualquiera que sea), requiere del perdón otorgado por la misma autoridad. Chimal metaforiza esta dinámica a la manera de una parábola bíblica en el relato "De la alianza": "El menor tenía el don de curar por la fe y sus manos sanaban, como por milagro, las heridas más graves. El mayor tenía fuerza sobrehumana en los puños, que empleaba para darle clientes a su hermano" (25). No es gratuito el sentido lúdico de este relato. Entre los espacios vacíos se encuentra entreverada con el humor una crítica despiadada a la conformación de la estructura religiosa.

La circularidad del paradigma se identifica claramente en "El error". Aquí, el personaje extasiado por la virtud de poder elevar su cuerpo cuarenta metros sobre la tierra reconoce el cumplimiento de una sentencia: “- ¡Sin duda, ustedes me dirán que no pueden con diez años de no comer carne, de no mirar mujer...!" (34). Este mismo sacrificio, lleno de virtud, comporta a su vez la sanción por el incumplimiento de otra sentencia: "El castigo (de la soberbia) tomó forma de rayo. Tronó el cuerpo en lo alto, cayeron cenizas y girones negros, y nosotros no pudimos ni contestarle que estaba en lo cierto" (34). Como una situación siempre incompleta por su singularidad paradójica, satisfacer un modelo de comportamiento indudablemente quebranta otro del mismo paradigma, insuficiente resulta el cumplimiento cabal, por esto el narrador se decanta por la indiferencia y la conformidad ante un resultado nunca variable. 


\section{Conciliación irónica de los contrarios}

El juego irónico en este libro de cuentos tiene como uno de sus recursos, siguiendo a Pere Ballart, el "desautomatizar los clichés, obligando al lector a cuestionarse, como si fuera la primera vez que los examinase, sus juicios y asunciones, y reclamando así la atención renovada para las ideas con que el texto se ha puesto a jugar. A jugar, en efecto, pues el ethos irónico prima sobre todo asentamiento el gusto por lo ocurrente" (1994: 451). La reflexión sobre los clichés lleva a Chimal a equiparar dos contrarios como parte de una misma lógica: la salvación y la perdición. El relato "Tao" da cuenta de este hecho:

A las diez, preocupada, Mamá piensa en su hija: la ve bailar y retorcerse como una loca por quién sabe qué antros y para qué hombres. Como en Babilonia. Seguro se les desnuda: seguro se les entrega y les hace movimientos lascivos y quién sabe qué otras cosas horrendas...

A las diez, preocupada, la hija piensa en Mamá: la ve bailar y retorcerse como una loca por el salón de culto. ¿Y para qué? Choca con la pared que da al taller mecánico, con la otra pared, cae al piso junto a quién sabe quién. Seguro canta o grita: seguro está convencida de que se entrega al Señor... (22)

El "gusto por lo ocurrente", del que habla Ballart, adquiere, en el texto de Chimal, fuerza expresiva debido al rebajamiento de lo divino a lo cotidiano. La inversión de valores es recurrente en Grey pese a que no se trata de una inversión tradicional entendida desde lo carnavalesco "poniendo lo alto en el lugar que corresponde a lo bajo, el detrás en vez del delante, tanto en el plano del espacio real como en el de la metáfora" (Bajtín, 1988: 334). Más bien se trata de una inversión capaz de presentarse en un mismo espacio narrativo; por esto, las figuras que representan lo religioso no pierden del todo su divinidad (los santos nunca dejan de serlo y Dios sigue mencionándose como figura central de la conformación religiosa, por ejemplo), sin embargo, son llevadas al terreno de lo cotidiano y lo humano.

El ejemplo más significativo, sin duda, es el brevísimo relato "Natural". En una línea, lo alto convive con lo bajo, proceso cuya intención provoca inevitablemente la risa: "La imagen de Santa Mócora sangraba cada veintiocho días" (33). Los alcances de la burla, que según Linda Hutcheon, son "una serie de valores que recorren la gama: de la indiferencia a la irrisión, del palmo de narices y de la risita socarrona, a la acrimonia irónica acumulativa" (1992: 181), trascienden la referencia del sangrado menstrual y toman como asidero principal las constantes creencias fanáticas en las lágrimas de sangre de los santos, es decir, en este caso la crítica está, en efecto, dirigida al creyente, a la grey.

Considero un ejemplo más de la conciliación de valores contrarios el relato "Altísmo". Entendido en su sentido más literal, el altísimo, suprema y absoluta deidad, es despojado de toda divinidad para explorar los intersticios de la naturaleza encontrándose con las más extrañas formas de emerger del espacio impreciso en que se encuentra. En este relato, como en el anterior, lo alto de la divinidad es relacionado con la mundanidad objetivada en el cuerpo humano. Transcribo el texto completo con la intención de ayudar a la comprensión del sentido:

Crece tan pero tan alto que alcanza la bóveda de lo inefable.

Mete la cabeza por un agujero, está lleno de estrellas, no le gusta. 
Mete la cabeza por otro agujero, sale por entre la tierra húmeda y es una lombriz, tampoco le gusta.

Mete la cabeza por otro agujero, se encuentra un ojo que todo lo ve, lo pica con la nariz, tampoco le gusta.

Mete la cabeza por otro agujero, es un túnel oscuro, se ve una luz en el fondo, en la luz está un ginecólogo, tampoco le gusta.

Mete la cabeza por otro agujero, se ve la textura de la palabra "paralelepípedo", se oye un intersticio de Lausana, no entiende (yo menos) y tampoco le gusta.

Mete la cabeza por otro agujero, es oscuro y fétido, se retira con algo de asco (No, tampoco le gusta).

Mete la cabeza por otro agujero y está viendo para abajo desde lo alto, y ve sus piernas que tiemblan y el suelo tan pero tan lejos, y siente vértigo. Se agarra de los bordes del agujero, se domina, y de pronto, de entre todo lo posible, escupe.

Caray. (78)

En los textos que componen Grey, la risa es un rasgo anclado a los mecanismos de la configuración humorística, pero es también, y sobre todo, la respuesta a una propuesta estética. De acuerdo con Bajtín, "la risa es una actitud estética hacia la realidad, definida pero intraducible al lenguaje de la lógica, es decir, es una determinada forma de la visión artística y de la cognición de la realidad y representa, por consiguiente, una determinada manera de estructurar la imagen artística, el argumento y el género" (2005: 245). Ya como recurso lúdico, ya como crítica o irreverencia, la risa se convierte en una posibilidad del lenguaje que permite el acercamiento del lector a la realidad y, con esto, su entendimiento.

La figuración irónica articula de principio a fin las estructuras narrativas de Grey, se trata de un recurso llevado a sus últimas consecuencias. Los distintos mecanismos operantes de la ironía en la compilación como la burla, el sarcasmo, el contraste, la ambivalencia y la antífrasis son recuperados para mostrar críticamente las debilidades, contradicciones o inconsistencias de las diversas estructuras religiosas, y para orientar la reflexión hacia las múltiples manifestaciones de la fe, a veces contrapunteadas con la naturaleza humana.

Grey es quizá uno de los libros más lúdicos de Alberto Chimal, sin embargo, la risa emanada de sus páginas es aquella que no permite sosiego para el lector crítico, revela, cual golpe en la cara, los contrastes de una conformación religiosa instaurada en cualquier comunidad. El sentido de este libro reside en evidenciar la condición del ser humano y sus inconsistencias como sujetos de fe.

\section{Bibliografía}

AVILÉS, Édgar Omar (2013): "Asombrar la noche: la premisa albertochimaliana". En Alberto CHIMAL: Manda fuego. Antología personal. México, FOEM, 13-29.

BALLART, Pere (1994): Eironeia. La figuración irónica en el discurso literario moderno. Barcelona, Quaderns Crema.

BAJTÍN, Mijail (1988): La cultura popular en la Edad Media y en el Renacimiento. El contexto de François Rabelais. Madrid, Alianza.

BAJTíN, Mijail (2005): Problemas en la poética de Dostoievski. México, FCE. 
CHIMAL, Alberto (2006): Grey, México, Era.

CHIMAL, Alberto: 83 novelas. México, 2010, http://www.lashistorias.com.mx/descarga/83_novelas.pdf, 07/05/2016.

CHIMAL, Alberto: "Generación Z en México: lo que no y lo que nunca", Revista crítica, 2011, http://revistacritica.com/contenidos-impresos/ensayo-literario/generacion-z-por-alberto-chimal/2, 15/03/2016.

HERBERT, Julián y Antonio ORTUÑO: "Escribir aquí y ahora. Una conversación sobre narrativa mexicana reciente", Letras libres 188 (2014), 40-44.

EREMIEV TORO, Boris: "El par simulación-disimulación y el arte de saber vivir", Alpha, 28 (2009), 169-180.

HERRERA, Jorge Luis (2009): “Alberto Chimal: realidad e irrealidad literaria”. En Voces en espiral. Entrevistas con escritores mexicanos contemporáneos. México, Universidad Veracruzana, 181-189.

HUTCHEON, Linda (1992): “Ironía, sátira, parodia”. En Hernán SILVA (comp.): De la ironía a lo grotesco (en algunos textos literarios hispanoamericanos). México, UAM-I, 171-193.

LAGMANOVICH, David: "El microrrelato hispánico: algunas reiteraciones", Iberoamericana, IX/36 (2009), 85-95.

MALDONADO, Tryno (ed.) (2008): Grandes hits. Nueva generación de narradores mexicanos, vol. I. México, Almadía.

TREVIÑO RAMÍREZ, Elsa M.: "Mínima textual y máxima semántica: brevedad y espacios literarios en la obra de Alberto Chimal", Les Ateliers du SAL 3 (2013), 80-94.

(C) Elsa López Arriaga

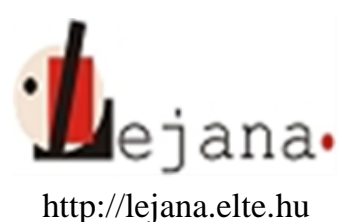

Universidad Eötvös Loránd, Departamento de Español, 1088 Budapest, Múzeum krt. 4/C

Recibido: 02 de junio de 2016

Aceptado: 18 de julio de 2016

Elsa López Arriaga: "Embates del humor en Grey de Alberto Chimal" 